\title{
DEVELOPMENT AND ANALYSIS OF A NEW APPROACH FOR SIMPLIFIED DETERMINATION OF THE HEATING AND THE COOLING LOADS OF LIVESTOCK BUILDINGS
}

\author{
Konstantin Kostov \\ Department of Mechanical Engineering, Manufacturing Engineering and Thermal Engineering \\ Faculty of Engineering and Pedagogy of Sliven ${ }^{1}$ \\ kostov_77@abv.bg \\ Ivan Ivanov \\ Department of Mechanical Engineering, Manufacturing Engineering and Thermal Engineering \\ Faculty of Engineering and Pedagogy of Sliven ${ }^{1}$ \\ ivov.ivan@abv.bg \\ Koycho Atanasov \\ Department of Mechanical Engineering, Manufacturing Engineering and Thermal Engineering \\ Faculty of Engineering and Pedagogy of Sliven ${ }^{1}$ \\ koycho_atanasov@abv.bg \\ ${ }^{1}$ Technical University of Sofia \\ 59 Burgasko Shose blvd., Sliven, Bulgaria, 8800
}

\begin{abstract}
Pig farming is a sector of animal husbandry, the development of which is great attention. The pork market occupies a large share in the trade in animal products. In the conditions of they do competition more efforts are made to improve the quality and reduce the cost of production. To achieve this goal, work is being done in several areas - development and expansion of the gene pool, improvement of the living environment in the premises for animal husbandry, reduction of energy costs. Along with the development of feeding technologies, it is necessary to create a suitable microclimate in the premises, in which the animals to realize their productive potential, which in turn is directly related to the use of heating and cooling systems. The design of these systems for both existing and new buildings is carried out according to generally accepted methodologies, which in turn require time for calculation and use of specialized software. The methodologies for determining the loads for heating and cooling of livestock buildings, in accordance with the current legislation in the Republic of Bulgaria, are compared with a new method proposed in this publication. The possibility to consider a livestock building from the point of view of the theory of heat exchange allows the use of the basic differential equations describing the dynamic interaction of the building with the environment. This description would be complete and complex to implement. Therefore, the method of dimensional analysis is used, which is based on generalized indicators, when fulfilling certain criteria of similarity. The aim of the new methodology is to shorten the design time and allow the rapid sizing of heating and cooling systems in livestock buildings. In developing the new methodology, the task was the proposed new approach to summarize the interaction of all physical parameters affecting the heat exchange between the building and the surrounding air, allowing to take into account changes in external (air temperature, wind speed, solar radiation intensity) and internal factors (heat given off by farm animals, lighting, process equipment and processes) affecting the heat exchange between the building and the ambient air.
\end{abstract}

Keywords: cooling load, heating load, livestock buildings, energy efficiency, dimension analysis.

DOI: $10.21303 / 2461-4262.2021 .001310$

\section{Introduction}

Increasing competition in the production of pork, makes farmers strive to reduce operating costs [1] and create optimal conditions for raising the animals. The formation of the microclimate in the animal breeding premises depends on a number of factors - the natural climatic conditions, the type and quality of the buildings, the type of construction materials, and the ways of raising the animals, their density and more. The natural climatic conditions that influence the formation of the microclimate in the premises where animals are kept include the temperature and relative humidity of the atmospheric air, the intensity of solar radiation, the number of sunny and cloudy days. 
The specific natural and climatic characteristics of the individual regions should be taken into account when constructing livestock buildings. It has been established that maintaining a permissible temperature [2] in bovine and porcine breeding establishments without additional heat supply facilities is possible at a minimum outdoor temperature of $-8{ }^{\circ} \mathrm{C}$ to $-12{ }^{\circ} \mathrm{C}$. In addition to temperature, certain levels of air velocity must be maintained to avoid high levels of turbulence [3]. Frequent wind gusts affect the operation of the ventilation, impairing the sustainability of indoor air exchange [4]. Modern animal production is concentrated in livestock farms of different sizes. Large buildings are being constructed for large farms, with no columns suitable for full mechanization and automation of production processes. Intensive breeding and high animal density increases the microclimate requirements in buildings, which are directly linked to the use of heating and cooling systems [5, 6]. For their part, cooling and heating systems must have low energy consumption and, where possible depending on the region, use the potential of renewable energy sources $[7,8]$. In order for these systems to be energy efficient on the other hand, the livestock buildings themselves need to be the such, both in the construction of new ones and in the repair of old ones, using building materials with good thermal insulation properties $[9,10]$. According to the current regulation, livestock buildings for animal breeding belong to production buildings and are not subject to classification by energy efficiency classes [11]. The basic assessment of their energy efficiency is presented by a generalized coefficient of heat transfer through the various enclosing structures of the building [12]. The determination of the individual coefficients of heat transfer for each enclosure and the calculation of the overall coefficient of heat transfer of the building is carried out by commonly accepted methodologies, which in turn require time to calculate and use specialized software [13-15].

The methodologies for determining the heating and cooling load of livestock farms have been developed on the basis of data on climate parameters obtained as a result of long-term observations. However, these methodologies do not solve problems related to increasing energy efficiency, the ability to regulate the operation of installations, reducing operating costs. This requires a significantly larger set of data that are not reported in the methodologies. Considering, analysing and summarizing the interaction of all physical parameters affecting the heat exchange between the building and the surrounding air is one such possibility considered in this publication.

\section{Materials and methods}

The object of consideration is a building with contemporary architecture. The embodiment of Fig. 1 the building is for breeding sows of small pigs with individual type «English boxes» [16]. The advantage of this type of individual boxing is that it reduces the possibility of trauma to young animals by the sow. Fig. 2 such boxes are shown which clearly show the protective tube grille.

Fig. 3, 4 show a horizontal and vertical section of the study building with dimensions $L=23.5 \mathrm{~m}$ length, $D=12 \mathrm{~m}$ width and $H_{1}=3.5 \mathrm{~m}, H=2.5 \mathrm{~m}$ for the respective height.

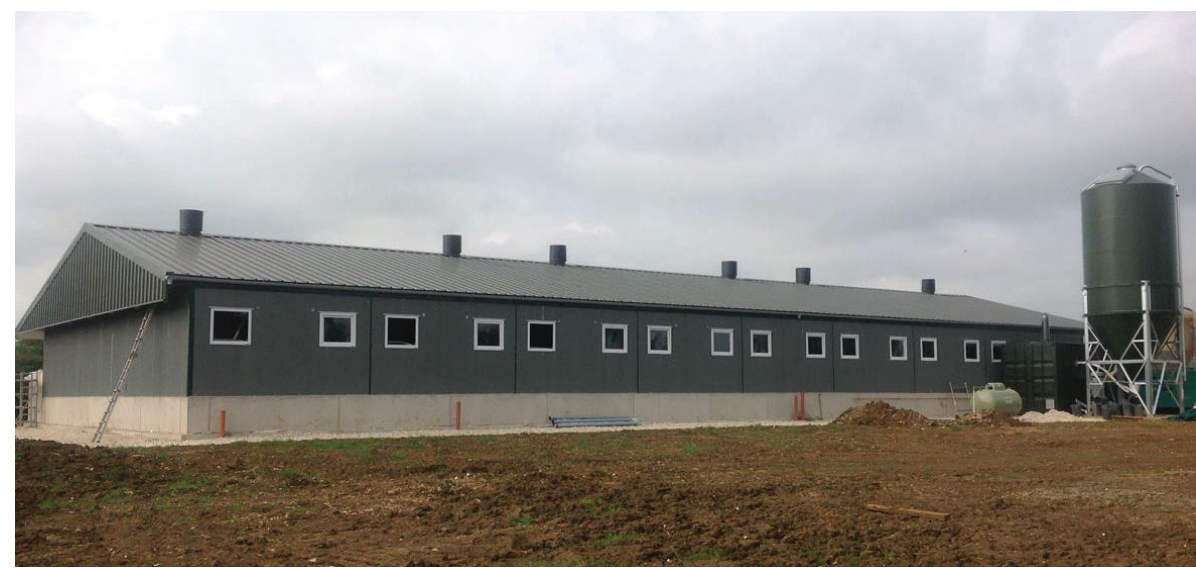

Fig. 1. Livestock building for sows with small pigs 


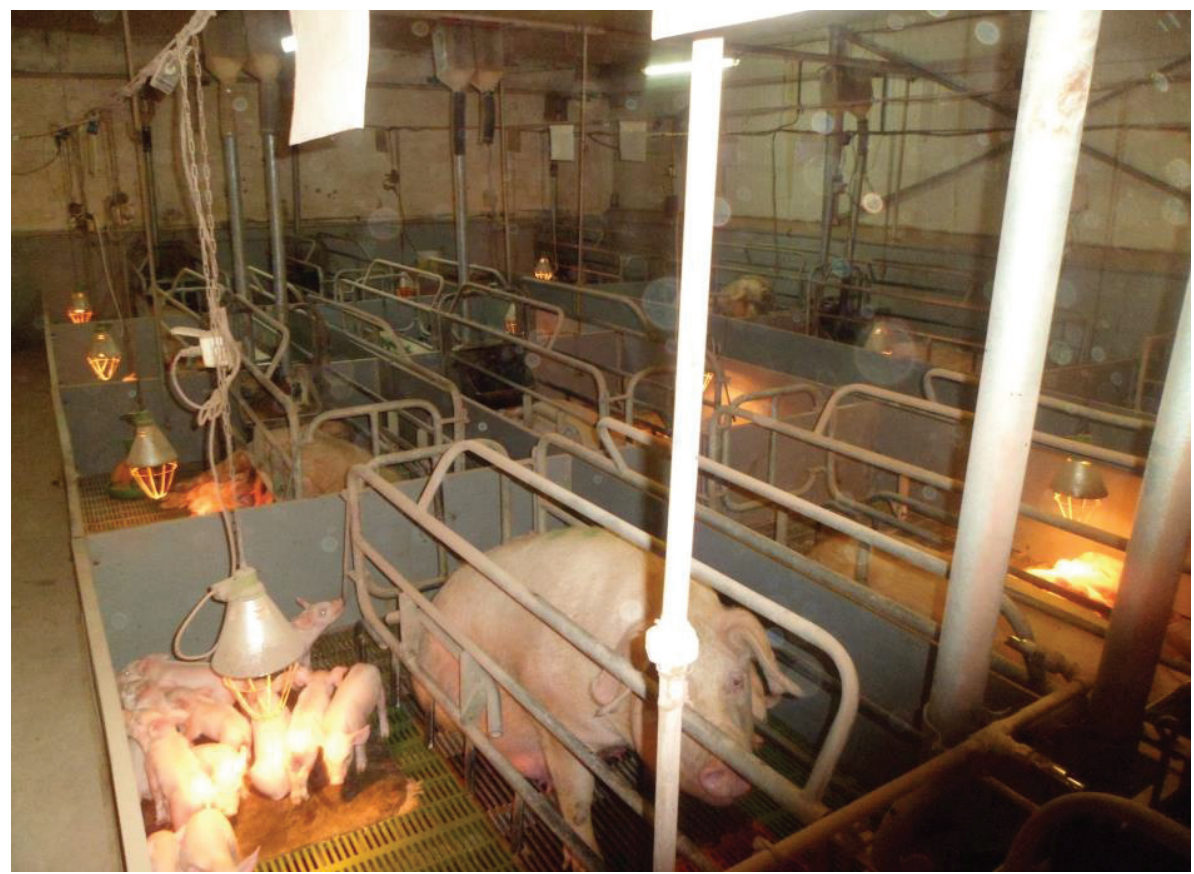

Fig. 2. Boxes for rearing small pigs

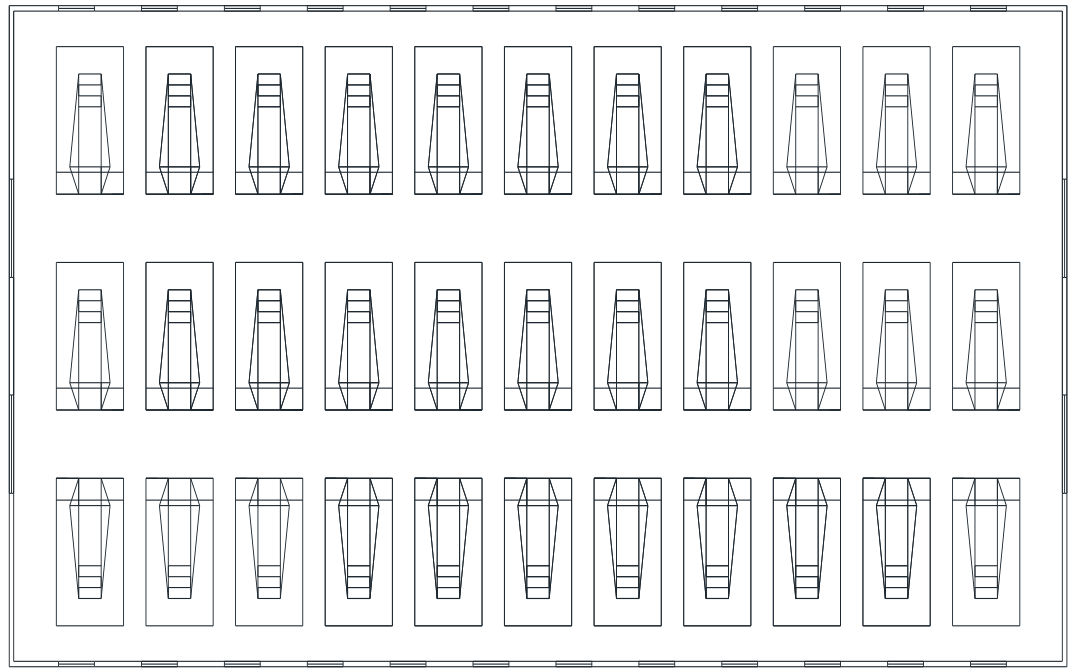

Fig. 3. Horizontal section of the examined building

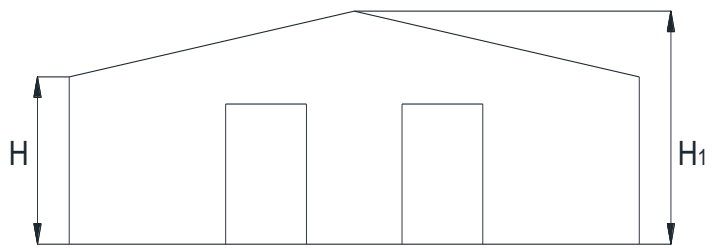

Fig. 4. Vertical section of the examined building

The building in question is monolithic made of concrete panels with thickness $\delta_{3}=200 \mathrm{~mm}$. The roof is double-sided by thermal panels with thickness $\delta r=150 \mathrm{~mm}$, without suspended ceiling. The floor of the building is without thermal insulation. The windows are made of PVC profiles and double glazed windows with a coefficient of heat transfer $U w=1.9 \mathrm{~W} / \mathrm{m}^{2} \cdot \mathrm{K}$. The doors of the building are metal with a coefficient of heat transfer $U d=2.2 \mathrm{~W} / \mathrm{m}^{2} \cdot \mathrm{K}$. The desired microclimate 
parameters in the building under consideration are $25^{\circ} \mathrm{C}$ and a relative humidity of $60 \%[16,17]$. These are values that meet the requirements of [11]. The indicated temperature and relative humidity are within the range of lactation requirements for pigs and piglets from 1 to 56 days old.

Fig. 5 shows the structure of the outer walls and the sloping roof.
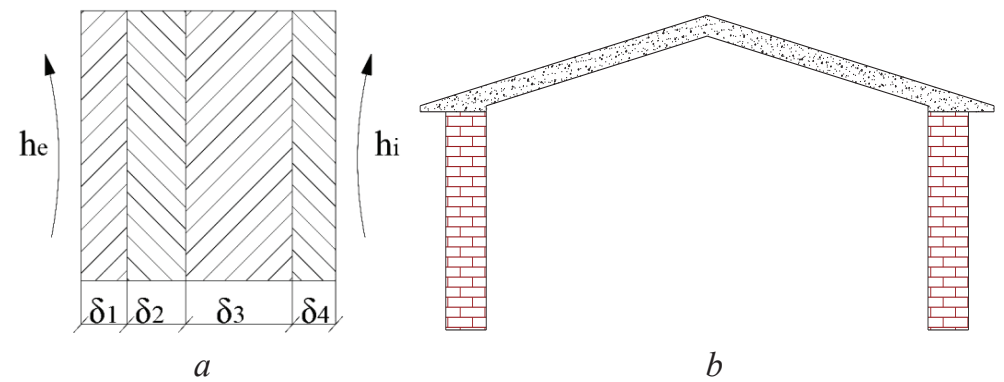

Fig. 5. Construction of the surrounding elements of the building: $a$-Structure of the outside walls; $b$ - Structure of the roof

Some assumptions have been made in determining the heating and cooling loads of the livestock building under study. In the calculation of the cooling load of the building, the possibility of offsetting any heat influxes from radiant or other heating of the animals imposed by the climatic features is envisaged. Due to the inability to predict the exact number of new-born animals, cases with variable numbers of animals ranging from 28 to 33 sows have been considered. This is done in order to determine the limits of the variation of heat released by animals [18-20]. These heat influxes are brought to a unit volume of the building, and heat sources for the heating of newborn animals are added to them $[21,22]$. When calculating the heating load of a building, the heat released by the animals is ignored. According to the current legislation $[23,24]$ the determination of the heating load of the building is carried out in a certain sequence. To determine the required heat of the building, the heat losses through the enclosures and the ventilation losses must be determined. First, the coefficients of thermal resistance for each enclosure are determined, and then the losses through it are determined.

Determination of the coefficient of heat transfer through the outer walls:

$$
\begin{gathered}
U_{\text {outer walls }}=\frac{1}{R_{\text {out.walls }}},\left[\frac{\mathrm{W}}{\mathrm{m}^{2} \cdot \mathrm{K}}\right], \\
R_{\text {out.walls }}=\frac{1}{h_{i}}+\sum_{i=1}^{n} \frac{\delta_{i}}{\lambda_{i}}+\frac{1}{h_{e}},\left[\frac{\mathrm{m}^{2} \cdot \mathrm{K}}{\mathrm{W}}\right],
\end{gathered}
$$

where:

$-\delta_{i}, \mathrm{~m}-$ thickness of the $i$-th layer of the wall;

$-\lambda_{i}, \mathrm{~W} / \mathrm{m} \cdot \mathrm{K}$ - coefficient of thermal conductivity of the air on the $i$-th layer of the wall;

$-h_{i}, \mathrm{~W} / \mathrm{m}^{2} \cdot \mathrm{K}$ - coefficient of heat transfer on the inside of the wall;

$-h_{e}, \mathrm{~W} / \mathrm{m}^{2} \cdot \mathrm{K}$ - coefficient of heat transfer on the outside of the wall.

Determination of the coefficient of heat transfer through the roof structure:

$$
\begin{gathered}
U_{\text {roof }}=\frac{1}{R_{\text {roof }}},\left[\frac{\mathrm{W}}{\mathrm{m}^{2} \cdot \mathrm{K}}\right], \\
R_{\text {roof }}=\frac{1}{h_{i}}+\sum_{j=1}^{n} \frac{\delta_{j}}{\lambda_{j}}+\frac{1}{h_{e}},\left[\frac{\mathrm{m}^{2} \cdot \mathrm{K}}{\mathrm{W}}\right],
\end{gathered}
$$

where:

$-\delta_{j}, \mathrm{~m}-$ thickness of the $j$-th layer of the roof structure;

$-\lambda_{j}, \mathrm{~W} / \mathrm{m} \cdot \mathrm{K}-$ coefficient of thermal conductivity of the air of the $j$-th layer of the roof structure; 
$-h_{i}, \mathrm{~W} / \mathrm{m}^{2} \cdot \mathrm{K}$ - coefficient of heat transfer from the inside of the roof structure;

$-h_{e}, \mathrm{~W} / \mathrm{m}^{2} \cdot \mathrm{K}$ - coefficient of heat transfer from the outside of the roof structure.

Determination of the ground heat transfer coefficient $-U f$.

To determine the coefficient of heat transfer through a floor slab on the ground (without underground floor) without thermal insulation on the periphery, it is necessary to determine the characteristic geometric dimensions $B^{\prime}$ and $d t$. Calculation of spatial characteristic $B^{\prime}$ :

$$
B^{\prime}=\frac{A_{\text {ground }}}{0.5 \cdot P}, \mathrm{~m}
$$

where:

$-A_{\text {ground }}, \mathrm{m}^{2}$ - floor area on the ground;

$-P, \mathrm{~m}-$ perimeter of the floor on the ground.

Determination of the reduced plate thickness $d t$ :

$$
d t=W+\lambda_{\text {ground }}(R s i+R f+R s e), \mathrm{m},
$$

where:

- $W, \mathrm{~m}$ - height of the aboveground part of wall to the floor slab;

$-R s i, \mathrm{~m}^{2} \cdot \mathrm{K} / \mathrm{W}$ - heat transfer resistance on the inner surface of the plate;

$-\lambda_{\text {ground }}, \mathrm{W} / \mathrm{m} \cdot \mathrm{K}$ - earth thermal conductivity factor;

$-R_{s e}, \mathrm{~m}^{2} \cdot \mathrm{K} / \mathrm{W}$ - heat transfer resistance of the outer surface of the plate;

$-R_{f}=\sum_{j=1}^{n} \delta_{j} / \lambda_{j}, \mathrm{~m}^{2} \cdot \mathrm{K} / \mathrm{W}$ - resistance of the thermal conductivity of the bottom plate.

At $d t<B^{\prime}$ :

$$
U f=\frac{2 \cdot \lambda_{\text {ground }}}{\pi \cdot B^{\prime}+d t} \ln \left(\frac{\pi \cdot B^{\prime}}{d t}+1\right),\left[\frac{\mathrm{W}}{\mathrm{m}^{2} \cdot \mathrm{K}}\right]
$$

At $d t>B^{\prime}$ :

$$
U f=\frac{\lambda_{\text {ground }}}{0.457 \cdot B^{\prime}+d t},\left[\frac{\mathrm{W}}{\mathrm{m}^{2} \cdot \mathrm{K}}\right] .
$$

The total heat transfer coefficient of the enclosing structure of the building is determined by the formula:

$$
U_{\text {gen. }}=\frac{H_{D}+H_{g}+H_{U}+H_{A}}{\sum_{k} A_{k}},\left[\frac{\mathrm{W}}{\mathrm{m}^{2} \cdot \mathrm{K}}\right] \text {, }
$$

where:

$-H_{D}, \mathrm{~W} / \mathrm{K}$ - coefficient of heat transfer by heat passing through the surrounding elements bordering on the outside air;

$-H_{g}, \mathrm{~W} / \mathrm{K}$ - coefficient of heat transfer by conduction through the earth;

$-H_{U}, \mathrm{~W} / \mathrm{K}$ - coefficient of heat transfer through heat passing through elements bordering on unheated or unheated zones;

$-H_{A}, \mathrm{~W} / \mathrm{K}$ - coefficient of heat transfer through heat passing through elements adjacent to adjoining buildings;

$-A_{k}, \mathrm{~m}^{2}$ - the area of the $k$-th element that surrounds the heated volume, determined by its outer dimensions.

Determination of the overall heat transfer coefficient is necessary to enable the investor to estimate what its energy costs will be for achieving the microclimate parameters in the animal breeding premises. 
After determining the overall heat transfer coefficient, the heat losses of the building are determined according to an approved methodology $[25,26]$.

The cooling load of the building is calculated by a known method [27-29].

Determining the heat flows.

Heat inflow through dense building elements lit by the sun $\left(\Phi_{d T, i}\right)$ :

$$
\Phi_{d T, i}=U \cdot A \cdot \Delta \theta_{C L}, \mathrm{~W},
$$

where:

$-U, \mathrm{~W} / \mathrm{m}^{2} \cdot \mathrm{K}-$ heat transfer coefficient;

$-A, \mathrm{~m}^{2}-$ area of the item;

$-\Delta \theta_{C L},{ }^{\circ} \mathrm{C}$ - temperature difference for cooling load determined under the following conditions - ambient temperature $35.5^{\circ} \mathrm{C}$ and room temperature $25.5^{\circ} \mathrm{C}$. When the conditions of a particular case differ from those specified, a corrected temperature difference value shall be used $-\Delta \theta_{C L, \text { cor }}$ :

$$
\Delta \theta_{C L, c o r}=\left[\left(\Delta \theta_{C L}+K_{m}\right) K_{c}+\left(25.5-\theta_{\text {int }}\right)+\left(\theta_{e}-29.4\right)\right] K_{v},{ }^{\circ} \mathrm{C},
$$

where:

$-K_{m}-$ correction for a given month of the year;

$-K_{c}$ - correction for colour surface;

$-\theta_{\text {int }},{ }^{\circ} \mathrm{C}$ - air temperature in the pig livestock buildings;

$-\theta_{e},{ }^{\circ} \mathrm{C}$ - average temperature of the outside air;

$-K_{v}$ - correction for ventilated attic space with outdoor air.

Average temperature of the outside air $\theta_{e}$, is determined by:

$$
\theta_{e}=\theta_{e, s}^{*}-\frac{\Theta}{2},{ }^{\circ} \mathrm{C},
$$

where:

$-\theta_{e, s}^{*},{ }^{\circ} \mathrm{C}$ - outdoor July temperatures;

$-\Theta,{ }^{\circ} \mathrm{C}$ - daily variations of temperature for different months and regions in Bulgaria.

For reasons enough natural light, the area of influence in the windows heat flux $\left(\Phi_{d, F T, i}\right)$ :

$$
\Phi_{d, F T, i}=U \cdot A^{\prime} \cdot\left(\theta_{e, t}-\theta_{i n t}\right), \mathrm{W}
$$

where:

- $U, \mathrm{~W} / \mathrm{m}^{2} \cdot \mathrm{K}$ - thermal transmittance through the glass elements;

$-A, \mathrm{~m}^{2}$ - area glazing elements;

$-\theta_{e, t},{ }^{\circ} \mathrm{C}$ - outside air temperature for the hour of the day is determined by:

$$
\theta_{e, t}=\theta_{e, s}^{*}-\Theta \frac{K_{t}}{100},{ }^{\circ} \mathrm{C},
$$

where $\Theta,{ }^{\circ} \mathrm{C}$ is daily variations of outside temperature, $K_{t}$ is correction of the outside temperature.

Cooling load from solar radiation through the sunned of the glazing element $\Phi_{d, F S L, i}$ :

$$
\Phi_{d, F S L, i}=A_{S L} \cdot \Phi_{t, \max } \cdot F_{S C} \cdot F_{C L}, \mathrm{~W},
$$

where:

$-A_{S L}, \mathrm{~m}^{2}$ - the surface of the glazing lit by the sun;

$-\Phi_{t, \max }, \mathrm{W} / \mathrm{m}-$ maximal heat flux of diffuse radiation;

$-F_{S C}, F_{C L}-$ correction factors. 
Cooling load from internal sources of animals $\Phi_{d, p}$ :

$$
\Phi_{d, p}=n \cdot \Phi_{s, p}, \mathrm{~W},
$$

where:

$-n$ - number of animals;

$-\Phi_{s, p}, \mathrm{~W}-$ heat flux of one animal.

Heat flux of evaporated humidity $\Phi_{h, C L, i}$ :

$$
\Phi_{h, C L, i}=1000 \Sigma \dot{\mathrm{m}}_{w, j} \cdot h_{w, j}, \mathrm{~W},
$$

where:

- $\dot{\mathrm{m}}_{w, j}, \mathrm{~kg} / \mathrm{h}$ - separate steam from a pig;

$-h_{w, j}, \mathrm{~kJ} / \mathrm{kg}$ - enthalpy of the steam at a temperature equal to the temperature of the skin of the pig.

Heat flux of ventilation $\Phi_{v, i n f, C L, i}$ :

$$
\Phi_{v, i n f, C L, i}=n \cdot V_{i n f, i} \cdot\left(h_{e}-h_{i n t, i}\right), \mathrm{W}
$$

where:

$-n$ - number of animals;

$-V_{\text {inf }, i}, \mathrm{~m}^{3} / \mathrm{s}$ - required amount of fresh air for one animal;

$-h_{e}, \mathrm{~kJ} / \mathrm{kg}$ - the enthalpy of the outside air;

$-h_{\text {int }, i}, \mathrm{~kJ} / \mathrm{kg}$ - the enthalpy of the air inside the building.

When considering and analysing the methodologies for determining the heating and cooling load of a facility for breeding industrial animals, in accordance with the current regulations and used in the design practice, it is seen that they are based on data on climatic parameters. In order to solve problems related to energy costs, possible deviations from the external calculation parameters or to regulate the operation of the installations, it is necessary to take into account all possible factors influencing the heat exchange between the building and the environment.

\section{Results and discussion}

If considered the building in terms of heat exchange theory, the basic differential equations [30-32] describing the dynamic interaction of the building with the environment can be used. This description would be complete and complicated to implement. If the method of dimension analysis is used instead of differential equations, taking into account all the influencing factors on the building's heat and cooling load, dependencies with applied character could be obtained, which could be used in practice quickly and relatively accurately (up to $5 \%$ difference from design calculations).

These dependencies will be universal in nature, but will only apply to buildings with a simple and close to the geometry of the building shown. Their versatility stems from the ability to quickly correct the basic thermal characteristics of the building components of the building, climatic factors and location features, as well as the ability to take into account internal heat sources in the building (number of animals, lighting, technological processes).

To summarize the reaction of the studied building with the environment in a cooling or heating regime have been defined complexes are displayed which contain specific values based on the analysis of the dimensions. In general form the dependence has the following appearance:

$$
Q=f(\Delta t, h e, q, \lambda, \delta),
$$

where:

- he, $\mathrm{W} / \mathrm{m}^{2} \cdot \mathrm{K}$ - heat transfer coefficient;

$-\lambda, \mathrm{W} / \mathrm{m} \cdot \mathrm{K}-$ thermal conductivity; 
$-\Delta t, \mathrm{~K}$ - temperature difference;

$-\delta, \mathrm{m}-$ thickness of the surrounding walls;

$-q, \mathrm{~W} / \mathrm{m}^{3}-$ specific individual biological heat of a farrow;

$-Q, \mathrm{~W} / \mathrm{m}^{3}$ - specific cooling or heating power, by reporting heat flows of the radiant heating designed for the piglets in the initial period of their growth.

Dependence (19) can be represented as a function depending on the type:

$$
Q=C \cdot \Delta t^{a} \cdot \alpha_{B}^{b} \cdot \delta^{c} \cdot \lambda^{d} \cdot q^{e}
$$

Given the objectives set, it seems acceptable to present (20) as a generalized dependence in accordance with similarity theory, using dimensional analysis in accordance with the recommendations [32]:

$$
T^{-1} \cdot H \cdot L^{-3}=\Theta^{a} \cdot\left(L^{-2} \cdot T^{-1} \cdot H \cdot \Theta^{-1}\right)^{b} \cdot L^{c} \cdot\left(L^{-1} \cdot T^{-1} \cdot H \cdot \Theta^{-1}\right)^{d} \cdot\left(L^{-3} \cdot T^{-1} \cdot H\right)^{e},
$$

where:

- $T$-dimensionless time;

$-H$ - dimensionless weight;

$-L$ - dimensionless length;

$-\Theta-$ dimensionless temperature, these indications are common in dimensional analysis.

After mathematical transformations of dependence (21), the final form of the criterion equation is obtained, which summarizes the interaction of the studied building with the environment and has the form:

$$
Q=\frac{\Delta t \cdot \alpha_{B}}{\delta} \cdot\left(\frac{q \cdot \delta}{\Delta t \cdot h_{e}}\right)^{e} \cdot\left(\frac{\lambda}{h_{e} \cdot \delta}\right)^{d}, \mathrm{~W} / \mathrm{m}^{3}
$$

Formula (22) defines the field of change of the individual external and internal factors affecting the heat exchange between the building and the environment. The dependency actually represents the power needed to heat or cool the building in question. In dimensionless form, equation (22) has the form:

$$
\frac{Q \cdot \delta}{\Delta t \cdot h_{e}}=\left(\frac{q \cdot \delta}{\Delta t \cdot h_{e}}\right)^{e} \cdot\left(\frac{\lambda}{h_{e} \cdot \delta}\right)^{d}
$$

Using the method, an analysis of the dimensions of the magnitudes that influence the heat exchange of the building with the ambient air, is derived a dependence taking into account the influence of different initial conditions relative to $1 \mathrm{~m}^{3}$. The following dependence (24) summarizes the studies carried out under different meteorological conditions and the varying number of animals raised and allows obtaining data on the specific heat influxes and heat losses of the various enclosing structures of the building under consideration. The dependence summarizes the results of the study using the coefficients obtained, which are analytically deduced by numerical experiments.

$$
Q=0.74 \cdot \frac{\Delta t \cdot h_{e}}{\delta}\left(\frac{q \cdot \delta}{\Delta t \cdot h_{e}}\right)^{-0.56} \cdot\left(\frac{\lambda}{h_{e} \cdot \delta}\right)^{1.39}, \mathrm{~W} / \mathrm{m}^{3}
$$

where:

$$
\begin{aligned}
& -\left(\frac{q \cdot \delta}{\Delta t \cdot h_{e}}\right) \text { and }\left(\frac{\lambda}{h_{e} \cdot \delta}\right) \text { - represent private numbers of similarity; } \\
& -\left(\frac{q \cdot \delta}{\Delta t \cdot h_{e}}\right) \text { - characterizes the relative influence of farmed animals and the heat exchange }
\end{aligned}
$$

with the environment at a certain temperature difference; 
$-\left(\frac{\lambda}{h_{e} \cdot \delta}\right)$ - reflects the relative value of the thermal conductivity of the walls and roof.

The data obtained for the functional dependence between the private criteria of similarity Fig. 6 show the possible interval of the required amount of heat or cold, under the accepted building codes and the possible meteorological conditions. They can be used for a quantitatively motivated choice of heating or cooling installation for the site in question.

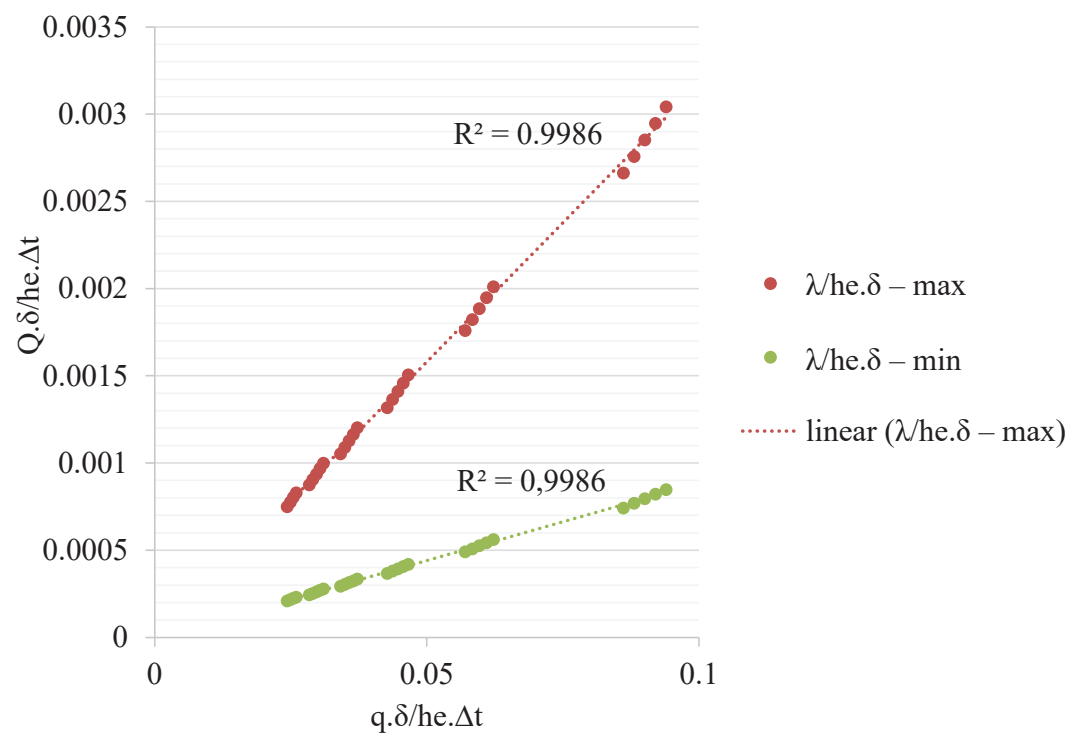

Fig. 6. Functional relationship between private similarity criteria

On this figure the limited results at $\lambda / h_{e} \cdot \delta-\min$ and $\lambda / h_{e} \cdot \delta-\max$, are shown. The minimal values of $\alpha_{B}$ are in case of lack of wind, and the maximum values are at wind with speed up to $12 \mathrm{~m} / \mathrm{s}$ (often reached in the area of the designed building). The graphics show the nature of the equations describing the interval of all heat flows of the studied building.

The constructed dependence according to equation (24) gives the possible range of change between at $\lambda / h_{e} \cdot \delta-\min$ and $\lambda / h_{e} \cdot \delta-\max$, it is necessary to evaluate how true and linear it is, and what is the quality of the approximation made.

To verify that the relationship between dependent and independent data is reasonably linear, i. e. the use of linear regression is justified, so-called correlation coefficient.

The basic correlation coefficient $R$ - makes sense of the cosine of the angle between the vector of the dependents and the vector of the independent experimental data and is calculated by the formula:

$$
R=\frac{\sum x_{i} y_{i}}{\sqrt{\sum x_{i}^{2} \sum y_{i}^{2}}}=0.9982
$$

It is accepted that the studied dependence has acceptable linearity if $R \geq 0.75[33,34]$. In our case, the studied dependence obviously has more than acceptable linearity.

In order to maintain the desired temperature in buildings of the type considered, it is necessary to take into account the climatic zone in which it is located, its architectural features and the desired number of animals raised. The calculations and analysis of the individual heat fluxes in the building clearly show the high proportion of biological heat released by the animals. Replacement of building structures or thermal insulation of enclosing elements can reduce heat fluxes through them from $4 \%$ to $8 \%$ in this particular case. The largest share of heat flows from heat transfer is through the roof, which confirms its mandatory thermal insulation.

During the calculations, the effect of the wind speed, which leads to an increase of the external heat transfer coefficient up to several times, is clearly visible. 
The derived private criterion equation summarizes the relationship between the building and the environment. The obtained results clearly define the relationships and the influence of each of the interconnected parameters influencing the microclimate in the livestock building. This allows considering which parameter has the greatest influence. Based on the conducted numerical experiments, the possible limits of change of the parameters are defined, in order to achieve an optimal microclimate for animal breeding.

The proposed method is strictly valid for the considered type of building for breeding sows with pigs with individual type «English boxes». With some restrictions, it can be applied to other buildings for breeding other animals, taking into account the conditions and specifics of each case - type of building, type and number of animals and others.

The presented method and the obtained results from the conducted research are a prerequisite for the materialization of a physical model of a building of the type considered. Such a physical model simulating a livestock farm would allow further research on the influence of each factor influencing the heat exchange between the building and the ambient air.

\section{Conclusion}

A new approach is proposed to determine the heating and cooling load of a building for piglets with small piglets based on the theory of similarity. The results are summarized in the form of a criterion equation using a method of dimensional analysis, which allows showing the relationship between the magnitude of interest and the values that affect its change. The obtained criterion dependence allows to quickly and with sufficient accuracy to determine the required power of a heating or cooling system, taking into accounting the influence of each factor influencing the heat exchange between the considered building and the environment. The ability to take into account the temperature difference between ambient air and indoor air, biological heat from animals, wind speed, solar radiation intensity, type and area of windows, thickness and structure of surrounding walls and roof, allows design calculations for a typical building in different conditions.

The expression in percentages of the individual heat fluxes of the studied building clearly shows that most of the biological heat is released by the animals. Thermal insulation of the enclosing walls and the roof of the building would reduce heat losses through them by $12 \%$. During the work on the publication and the calculations, it became clear the influence of wind speed and especially the increase of the external heat transfer coefficient up to several times - from 9.5 to $26.13 \mathrm{~W} / \mathrm{m}^{2} \cdot \mathrm{K}$. The obtained results are oriented to the practice in order to create a suitable microclimate in the livestock buildings, with reduced heating and cooling costs.

\section{Acknowledgements}

The author/s would like to thank the Research and Development Sector at the Technical University of Sofia for the financial support.

\section{References}

[1] Beloev, H. I., Terziev, A. K., Iliev, I. K., Ivanov, M. P. (2020). Energy efficiency improvement in farming equipment, for agricultural holdings. IOP Conference Series: Materials Science and Engineering, 977, 012011. doi: https://oi.org/10.1088/ $1757-899 x / 977 / 1 / 012011$

[2] NAREDBA No. 44 ot 20.04.2006 g. za veterinarnomeditsinskite iziskvaniya km zhivotnovdnite obekti. Available at: https:// www.mzh.government.bg/odz-stzagora/Libraries/\%D0\%9D\%D0\%B0\%D1\%80\%D0\%B5\%D0\%B4\%D0\%B1\%D0\%B8/ Naredba_44-20_04_2006.sflb.ashx

[3] Denev, I., Tsankov, P., Antonov, I. (2016). CFD simulation of the influence of air conditioner on the turbulence intensity in residential room. Proceedings of University of Ruse, 55 (1.2), 97-101. Available at: http://conf.uni-ruse.bg/bg/docs/ cp16/1.2/1.2-18.pdf

[4] Andonov, K., Daskalov, P., Martev, K. (1989). Microclimate system for livestock building with controlled natural ventilation. Agricultural Engineering, 2, 55-62.

[5] Mós, J. V. do N., Nascimento, S. T., Murata, L. S., dos Santos, V. M., Neto, A. J. S., de Oliveira, E. M. et. al. (2020). Thermal comfort of sows in free-range system in Brazilian Savanna. Journal of Thermal Biology, 88, 102489. doi: https://doi.org/ 10.1016/j.jtherbio.2019.102489 
[6] Firfiris, V. K., Martzopoulou, A. G., Kotsopoulos, T. A. (2019). Passive cooling systems in livestock buildings towards energy saving: A critical review. Energy and Buildings, 202, 109368. doi: https://doi.org/10.1016/j.enbuild.2019.109368

[7] Kostov, P., Petrova, R., Atanasov, K., Krastev, N. (2009). Energy consumption and its influence on the environment and eco-systems. Proceedings of the C\&SEE International Solid Waste Management Symposium. Vienna, 107-112.

[8] Schauberger, G., Hennig-Pauka, I., Zollitsch, W., Hörtenhuber, S. J., Baumgartner, J., Niebuhr, K. et. al. (2020). Efficacy of adaptation measures to alleviate heat stress in confined livestock buildings in temperate climate zones. Biosystems Engineering, 200, 157-175. doi: https://doi.org/10.1016/j.biosystemseng.2020.09.010

[9] Trifonov, A. (2016). Vliyanie na mikroklimata vrhu fiziologichnoto sstoyanie i produktivnostta na zhivotnite. Zemedelska tehnika. Available at: http://zemedelskatehnika.com/влияние-на-микроклимата-върху-физиол/

[10] Petkova-Slipets, R., Yordanov, K., Zlateva, P. (2020). A Comparative Thermal Analysis of Walls Composed of Traditional and Alternative Building Materials. Civil and Environmental Engineering, 16 (2), 388-395. doi: https://doi.org/10.2478/ cee-2020-0039

[11] NAREDBA E-RD-04-05/8.09.2016 g. Za opredelyane na pokazatelite za razhod na energiya, energiynite harakteristiki na predpriyatiya, promishleni sistemi i sistemi za vnshno izkustveno osvetlenie, kakto i za opredelyane na usloviyata i reda za izvrshvane na obsledv. Ministry of Energy of the Republic of Bulgaria. Available at: https://www.me.government.bg/bg/ library/naredba-e-rd-04-05-8-09-2016-g-za-opredelyane-na-pokazatelite-za-razhod-na-energiya-energiinite-harakteristiki-na-predpriyatiya-promishleni-sistemi-i-sistemi-za-vanshno-izkustveno-osvetlenie-kakto-i-za-opredelyane-na-usloviyata-i-reda-za-izvarshvane-na-obsledv-592-c78-m1517-3.html

[12] Terziev, A., Stoyak, V., Ushakov, V., Brazhanova, D., Suleimanov, S. (2021). Analysis of the opportunities for improving energy efficiency in public buildings. IOP Conference Series: Materials Science and Engineering, 1019, 012021. doi: https:// doi.org/10.1088/1757-899x/1019/1/012021

[13] Najjar, M. K., Figueiredo, K., Hammad, A. W. A., Tam, V. W. Y., Evangelista, A. C. J., Haddad, A. (2019). A framework to estimate heat energy loss in building operation. Journal of Cleaner Production, 235, 789-800. doi: https://doi.org/10.1016/ j.jclepro.2019.07.026

[14] InstalSistem 4 OVK. Available at: http://software.guerov.org/design-software-menu/design-software-menu/instalsystemovk.html

[15] Softuer za proektirane na OVK sistemi - HK Select. Available at: https://www.hoval.bg/produki/hk-select-hvacsystemdesign-software-for-hvac-engineers

[16] Nenov, C., Dinev, D. (1986). Directory of hygiene and construction in industrial livestock. Sofia.

[17] Renaudeau, D., Collin, A., Yahav, S., de Basilio, V., Gourdine, J. L., Collier, R. J. (2012). Adaptation to hot climate and strategies to alleviate heat stress in livestock production. Animal, 6 (5), 707-728. doi: https://doi.org/10.1017/s1751731111002448

[18] Wen, X., Wu, W., Fang, W., Tang, S., Xin, H., Xie, J., Zhang, H. (2019). Effects of long-term heat exposure on cholesterol metabolism and immune responses in growing pigs. Livestock Science, 230, 103857. doi: https://doi.org/10.1016/j.livsci.2019.103857

[19] Gonzalez-Rivas, P. A., Chauhan, S. S., Ha, M., Fegan, N., Dunshea, F. R., Warner, R. D. (2020). Effects of heat stress on animal physiology, metabolism, and meat quality: A review. Meat Science, 162, 108025. doi: https://doi.org/10.1016/ j.meatsci.2019.108025

[20] Huynh, T. T. T., Aarnink, A. J. A., Gerrits, W. J. J., Heetkamp, M. J. H., Canh, T. T., Spoolder, H. A. M. et. al. (2005). Thermal behaviour of growing pigs in response to high temperature and humidity. Applied Animal Behaviour Science, 91 (1-2), 1-16. doi: https://doi.org/10.1016/j.applanim.2004.10.020

[21] Pyykkönen, M. (1992). The use of heated models to describe the thermal environment in shelters for farm animals. Agricultural and Food Science, 1 (6), 539-545. doi: https://doi.org/10.23986/afsci.72466

[22] Quiniou, N., Noblet, J., van Milgen, J., Dubois, S. (2001). Modelling heat production and energy balance in group-housed growing pigs exposed to low or high ambient temperatures. British Journal of Nutrition, 85 (1), 97-106. doi: https:// doi.org/10.1079/bjn2000217

[23] Naredba No. 7 ot 2004 g. za energiyna efektivnosti na sgradi (zagl. izm. - DV, br. 85 ot 2009g., izm. - dv, br. 27 ot 2015 g., v sila ot 15.07.2015 g.). Available at: https://www.mrrb.bg/static/media/ups/articles/attachments/Наредба\%207\%20за\%20 енергийна\%20ефективност\%20на\%20сградиb191b6b8919debd538c09ed26f9c9d25.pdf

[24] Naredba No. 15 ot 28 yuli 2005 g. za tehnicheski pravila i normativi za proektirane, izgrazhdane i eksploatatsiya na obektite i sorzheniyata za proizvodstvo, prenos i razpredelenie na toplinna energiya. Available at: https://www.mrrb.bg/static/media/ ups/articles/attachments/cb8c6f276e53468170a8c6fea21e224d.pdf

[25] Krasteva, A., Koev, K., Peev, V. (2008). Modeling of the heat losses and the consumed heat for a definite site. Scientific Papers of the University of Ruse, 47 (9), 168-173. Available at: http://conf.uni-ruse.bg/bg/docs/cp/9/9-35.pdf

[26] Stamov, S. (1990). Guide to Heating, Ventilation and Air-Conditioning, Part 1. Technology. Sofia. 
[27] Cooper, K., Parsons, D. J., Demmers, T. (1998). A Thermal Balance Model for Livestock Buildings for use in Climate Change Studies. Journal of Agricultural Engineering Research, 69 (1), 43-52. doi: https://doi.org/10.1006/jaer.1997.0223

[28] Turnpenny, J. R., McArthur, A. J., Clark, J. A., Wathes, C. M. (2000). Thermal balance of livestock. Agricultural and Forest Meteorology, 101 (1), 15-27. doi: https://doi.org/10.1016/s0168-1923(99)00159-8

[29] Turnpenny, J. R., Wathes, C. M., Clark, J. A., McArthur, A. J. (2000). Thermal balance of livestock. Agricultural and Forest Meteorology, 101 (1), 29-52. doi: https://doi.org/10.1016/s0168-1923(99)00157-4

[30] Madrid, C. N., Alhama, F. (2006). Discrimination: A fundamental and necessary extension of classical dimensional analysis theory. International Communications in Heat and Mass Transfer, 33 (3), 287-294. doi: https://doi.org/10.1016/ j.icheatmasstransfer.2005.11.002

[31] Huntley, H. (1967). Dimensional analysis. Dover, 158.

[32] Kostov, P., Atanasov, D. (2002). Similarity numbers for combustion of gas in a restricted rotary stream by diffusion. Mechanics of machines, 6, 9-10.

[33] Skorniakov, V. (2019). On asymptotic normality of certain linear rank statistics. Statistics \& Probability Letters, 145, 63-73. doi: https://doi.org/10.1016/j.spl.2018.08.016

[34] Xiang, J. X. (2019). Estimation of minimum and maximum correlation coefficients. Statistics \& Probability Letters, 145, 81-88. doi: https://doi.org/10.1016/j.spl.2018.08.010

How to cite: Kostov, K., Ivanov, I., Atanasov, K. (2021). Development and analysis of a new approach for simplified determination of the heating and the cooling loads of livestock buildings. EUREKA: Physics and Engineering, 2, 87-98. doi: https://doi.org/ 10.21303/2461-4262.2021.001310 